\title{
Automatic Smart Parking and Reservation System Using IOT
}

\author{
Basavaraj Chougula', Arun Tigadi ${ }^{2}$, Sushant Jadhav ${ }^{3}$ and Gujanatti Rudrappa ${ }^{4}$ \\ ${ }_{1,2,3,4}$ Department of Department of Electronics and Communication Engineering, \\ KLE Dr. M. S. Sheshgiri College of Engineering and Technology,Belagavi, India
}

\section{ABSTRACT}

In recent years the number of vehicles increased drastically and many times the car owners struggle to find the proper parking space within the city. IoT has great potential in implementing many of the smart city infrastructure requirements. Traffic congestion and the scarcity of car parking space have given a lot of opportunity for the research scholars to work in this field. In this paper we have proposed a smart car parking and reservation system. The proposed system is being controlled by an android app so as to reduce human intervention. This system reduces the traffic congestion and hence fuel consumption. To book the free slot for parking in advance is being done with the help of web application either using PC or mobile phone. This system can be used to book a free car parking slot within city.

\section{KEY WORDS: ANDROID, ARDUINO, INTERNET OF THINGS, RESERVATION SYSTEM, SMART PARKING.}

\section{INTRODUCTION}

Internet of Things (IoT) is a technology where in all the smart nodes will be connected to each other with the help of internet. Accessing the parameters from the remote sensors became a reality because of IoT. Such connected nodes generate a huge amount of data which will be stored in the cloud. In this proposed design we have made use of concept of IoT to book a free car parking slot. The main aim of our design is to give the information related to the available free car parking slots on user fingertip. It will be more convenient to the car owners to reduce the effort in finding the free car parking slots within the city.

\section{ARTICLE INFORMATION}

*Corresponding Author: basuec10@gmail.com

Received 15th Oct 2020 Accepted after revision 29th Dec 2020

Print ISSN: 0974-6455 Online ISSN: 2321-4007 CODEN: BBRCBA

Thomson Reuters ISI Web of Science Clarivate Analytics USA and Crossref Indexed Journal

\section{Clarivate
Analytics}

NAAS Journal Score 2020 (4.31)

A Society of Science and Nature Publication,

Bhopal India 2020. All rights reserved.

Online Contents Available at: http//www.bbrc.in/

Doi: http://dx.doi.org/10.21786/bbrc/13.13/15
We have made use of an optimal architecture for the proposed design. In this design the traffic congestion is reduced due to confirmed parking slot and pre booking option. Hence it will save fuel and hence the carbon footprint. Recently the Indian government has launched a proposal called as smart city, where in the whole city will be developed so as to make the life of the people living there more comfortable and flexible. In such conceptualization the smart parking system plays a vital role.

In large shopping complexes many times the vehicle owner struggle to find the parking place and end up wasting a lot of their valuable time. Now to avoid such situations we have come up with a solution where in the whole parking problem can be solved. Even this system has a pre booking and cancellation option. We can book a parking slot in advance and save traffic congestion which reduces fuel consumption of the vehicle. The whole work has been divided into multiple sub sections. The description starts with literature review, where a brief description about the work already done in this domain has been discussed. Followed by methodology in terms of a simple flowchart has been explained. 
Then the preceding part of the paper explains about its implementation and functional working.

Literature Survey: (Mendiratta et al., 2017), (Krasner and Katz, 2016), (Suhr and Jung, 2016) have proposed work is using ultrasonic sensor to detect the parking slot. The parking slot status is updated on internet using ESP8266 Wi-Fi module. (Khanna and Anand, 2016), (Zheng et al., 2015), have proposed mobile application for parking system and an on-site deployment of an IoT module. It is used to monitor and provide the availability of each single parking space. (Lambrinos and Dosis, 2013), (Polycarpou et al., 2013), (Geng and Cassandras, 2011), have proposed system called DisAssist. It will help people with disabilities for finding available parking slots. It uses wireless and mobile communication. It integrates sensors and smart phones. (Chinrungrueng et al., 2007) and (Chinrungrueng et al., 2006) proposed WSN for traffic monitoring. Observation was that this could be applied to monitor vehicles in parking garage. Then drivers are informed about available parking spaces. WSN modified for parking garage.

\section{METHODOLOGY}

A. Parking slot booking: Since the drivers keep on roaming around seeking out for decent parking, using this feature they can book the space for car parking in advance. They just need to install the app and can select the vacant slot. For this feature, they don't have to pay anything in advance. Once booking is done, the server will be updated accordingly. If the user is new, he/she has to register with his/her credentials and get access to the app. The old users can simply log in into the app by using the user id and password that was given by the user at the time of registration.

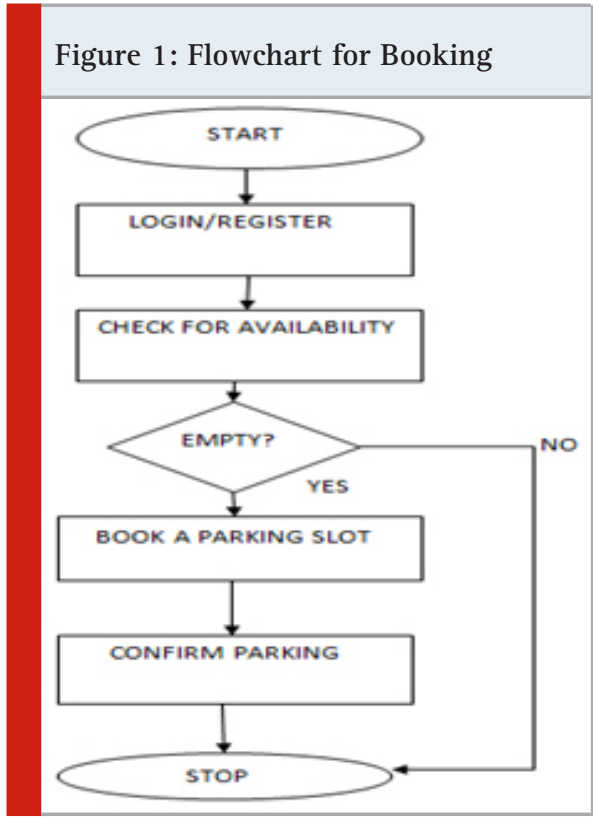

After the user has logged in into the app, he/she checks for the availability of the parking slots and if a slot is empty then the user books the particular slot. The status is updated in the app and the user will receive a confirmation message on successful booking. As shown in the (Figure 1) is the simple flow chart for booking. Where in we verify for the registered user and then check for the availability of the parking slot. If slot is empty then a confirmation will be displayed on the app.

B. Vehicle Entry: (Figure 2) shows the flow chart for Vehicle Entry.

Figure 2: Flowchart for Vehicle Entry

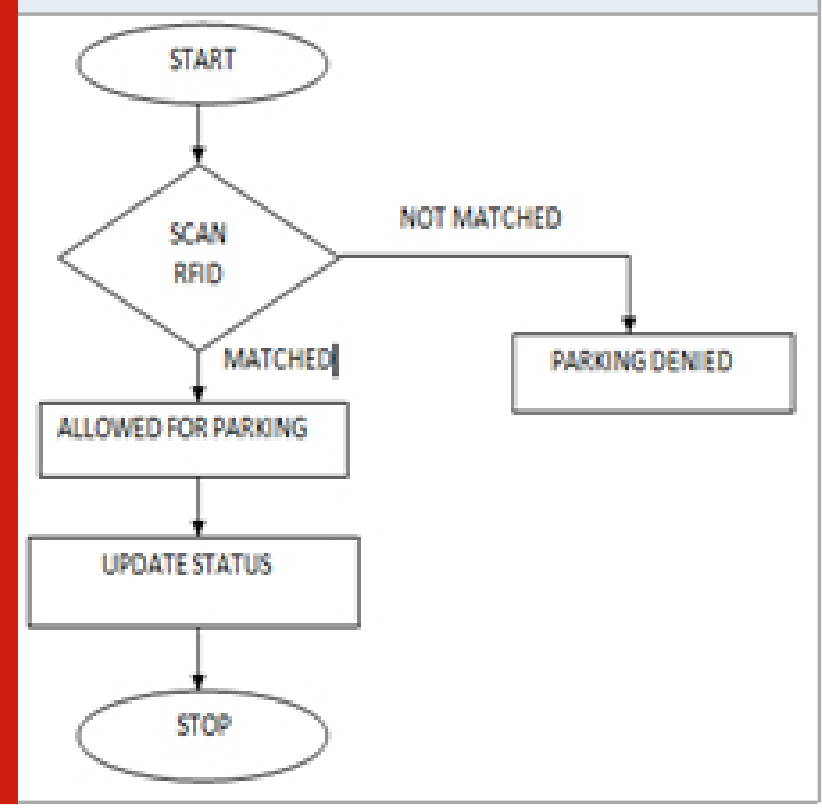

\section{Pseudo Code for Vehicle Entry}

Input: the RFID code C;

Output: Parking Slot Status S;

Initialization: Parking Slot $\mathrm{S}=0$;

1: for each vehicle entry scan RFID code C do

2: if $\mathrm{C}$ matches in $\mathrm{C} 1$ then

3: $\mathrm{S}$ to 1 ;

4: end if

5: end for

6: return S 1;

As shown above is the Pseudo code for the vehicle entry. The QR code generated after booking the parking slot is taken as variable C. This code will be varied at the entry of the parking. The variable $\mathrm{S}$ is used to indicate the availability of the slots. If $\mathrm{S}=0$ indicates a particular slot is free. Once after booking happens by a user the $\mathrm{S}$ immediately gets updated to $S=1$. This information will be available to the user in the app and to the app admin at the background.

Whenever, the registered user books a parking a slot, a unique RFID tag will be generated as shown in (Figure 3) and sent to the user. When the vehicle enters the parking space, it checks for the same. If the tag generated and the tags scanned by the user are same, then the vehicle is allowed for parking. If the tags do not match, then 
parking is denied for that vehicle. After parking a vehicle in the parking slot, parking slot details will be updated i.e slot is occupied, as shown in (Figure 4). In (Figure 4), occupied column ' 1 ' indicates that vehicle is present in the slot and ' 0 ' indicates slot is empty. And this updated information will be shown to the user with the help of mobile application.

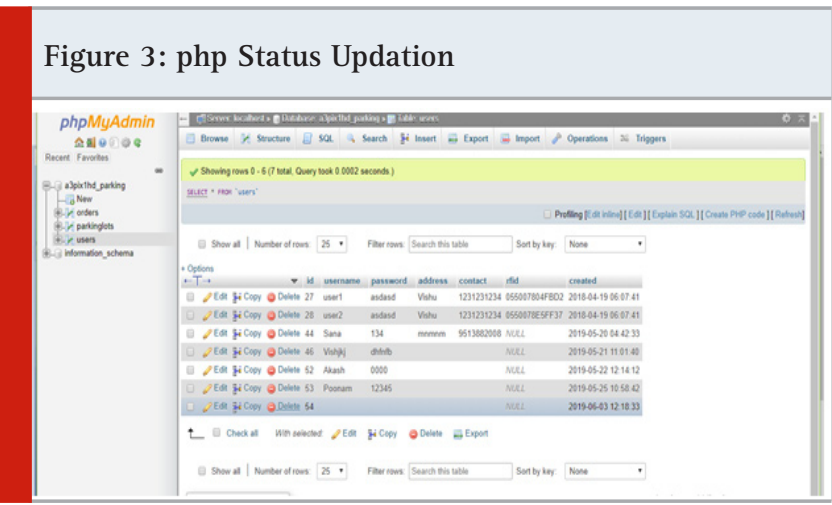

Figure 4: php Parking Status

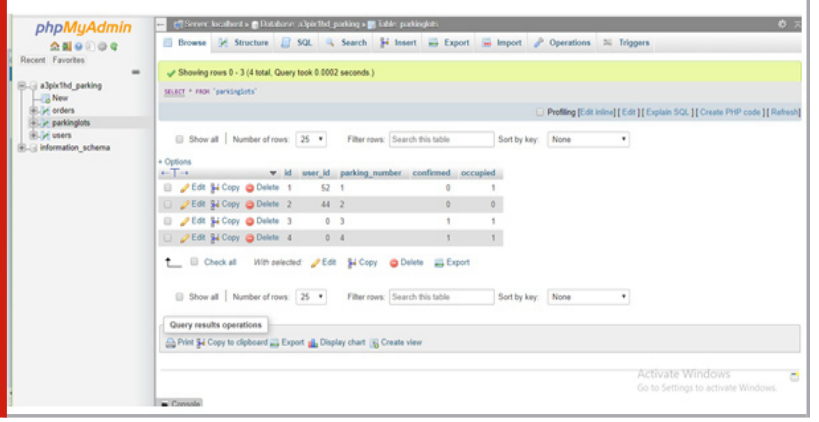

Figure 5: php Booking Orders

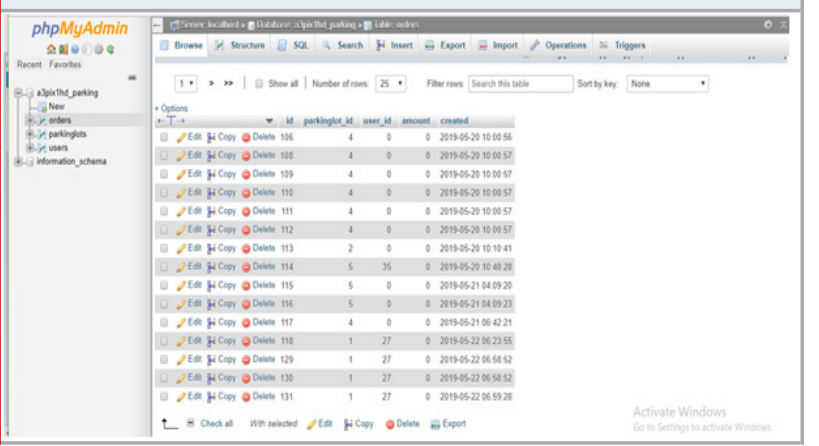

The app admin will get the detailed consolidated information as shown in the below (Figure 5) consisting of user ids, parking slots booked, available, date and time.

D. Vehicle Exit: (Figure 6) shows the flow chart for Vehicle Exit.

\section{E. Pseudo Code for Vehicle Exit}

Input: the Sensor Output C;

Output: Parking Slot Status S;

Initialization: Parking Slot $\mathrm{S}=1$;
$1:$ if $\mathrm{C}=1$ then

2: $\mathrm{S}$ to 0 ;

3: end if

4: return S 0;

Figure 6: Vehicle Exit

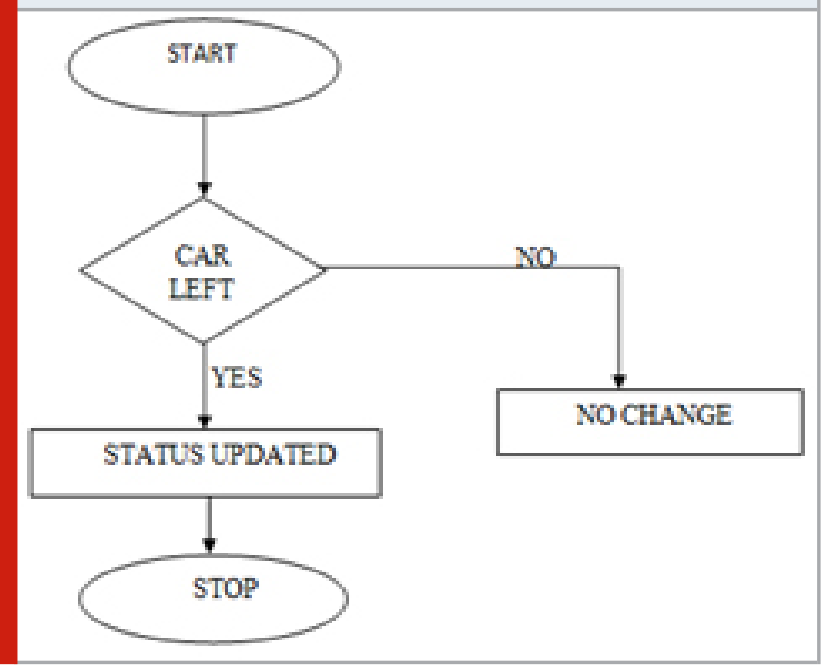

At the time of exit, the user is required to scan the RFID tag of the vehicle. Upon successful payment, that particular slot will be available as vacant again and the database will be updated accordingly i.e $S=0$, so that next user can use the same. This parking system is useful for parks, street side and malls parking. The entire parking system information will be stored on the server. This information consists of number of empty slots, number of occupied slots etc. The secured gateways are used to access the system information. The parking spaces present in the city is stored on the main server database.

F. Registration system: Initially, the user has to register the details. It stores his necessary details into the server. Once the user is registered, he is allowed to sign in to his account and allowed to book a parking slot. Once user vehicle reaches the parking lot, the RFID tag is verified. This is done using a RFID reader module. After the verification, the vehicle is permitted to enter the parking lot. The nearest available slot number is given. Then at the exit barricade the RFID card is again verified while exiting from the parking lot.

Features of Hardware Architecutre: Below are the hardware details.
i. Arduino UNO
ii. ESP Module
iii. LDR(Light Dependent Resistor) Sensor
iv. RF ID Reader Module
v. XAMPP SERVER
vi. NOTEPAD++ EDITOR
vii. MySQL
viii. PhpMyAdmin 
A. ARDUINO UNO (ATmega328p): The Microcontroller ATmega328p is used for the system. This microcontroller has input and output pins. These pins will help to interface with external world. There are $14 \mathrm{I} / 0$ pins for digital data. And 6 pins are for analog data. This microcontroller will be able to read input from sensor. For internet connectivity this board is connected to an Ethernet cable (standard RJ-45).
Figure 7: IoT System block diagram

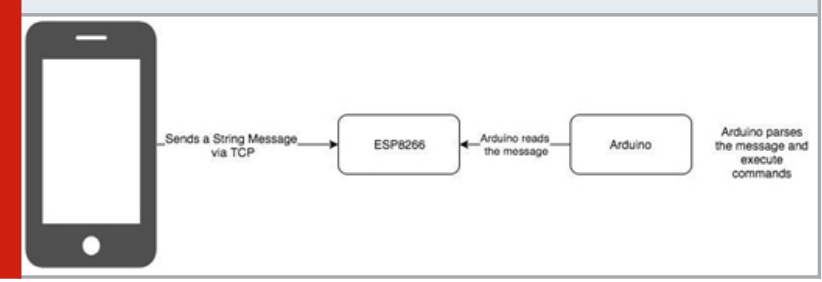

Table 1. System parameters

\begin{tabular}{|c|c|c|}
\hline Categories & Items & Parameters \\
\hline \multirow[t]{10}{*}{ Wi-Fi (ESP8266) } & Certification & Wi-Fi Alliance \\
\hline & Protocols & $802.11 \mathrm{~b} / \mathrm{g} / \mathrm{n}(\mathrm{HT} 20)$ \\
\hline & Frequency Range & $2.4 \mathrm{G} \sim 2.5 \mathrm{G}(2400 \mathrm{M} \sim 2483.5 \mathrm{M})$ \\
\hline & \multirow[t]{3}{*}{ TX Power } & $802.11 \mathrm{~b}:+20 \mathrm{dBm}$ \\
\hline & & $802.11 \mathrm{~g}:+17 \mathrm{dBm}$ \\
\hline & & $802.11 \mathrm{n}:+14 \mathrm{dBm}$ \\
\hline & \multirow[t]{3}{*}{ RX Sensitivity } & 802.11b: $-91 \mathrm{dBm}(11 \mathrm{Mbps})$ \\
\hline & & 802.11g: $-75 \mathrm{dBm}(54 \mathrm{Mbps})$ \\
\hline & & $802.11 \mathrm{n}:-75 \mathrm{dBm}(\mathrm{MCS} 7)$ \\
\hline & Antenna & PCB Trace, External, IPEX Connector, Ceramic Chip \\
\hline \multirow[t]{7}{*}{ Hardware } & CPU & Tensilica L106 32-bit processor \\
\hline & Peripheral Interface & $\begin{array}{l}\text { UART/SDIO/SPI/I2C/I2S/IR Remote Control } \\
\text { GPIO/ADC/PWM/LED Light \& Button }\end{array}$ \\
\hline & Operating Voltage & $2.5 \mathrm{~V} \sim 3.6 \mathrm{~V}$ \\
\hline & Operating current & Average value: $80 \mathrm{~mA}$ \\
\hline & Operating Temperature Range & $-40^{\circ} \mathrm{C} \sim 125^{\circ} \mathrm{C}$ \\
\hline & Package Size & QFN32-pin (5 mm x $5 \mathrm{~mm}$ ) \\
\hline & External Interface & - \\
\hline \multirow[t]{3}{*}{ Software } & Wi-Fi Mode & Station/SoftAP/SoftAP+Station \\
\hline & Firmware Upgrade & UART Download/OTA (via network) \\
\hline & User Configuration & AT Instruction Set, Cloud Server, Android/iOS App \\
\hline
\end{tabular}

Figure 8: Sensor Stands

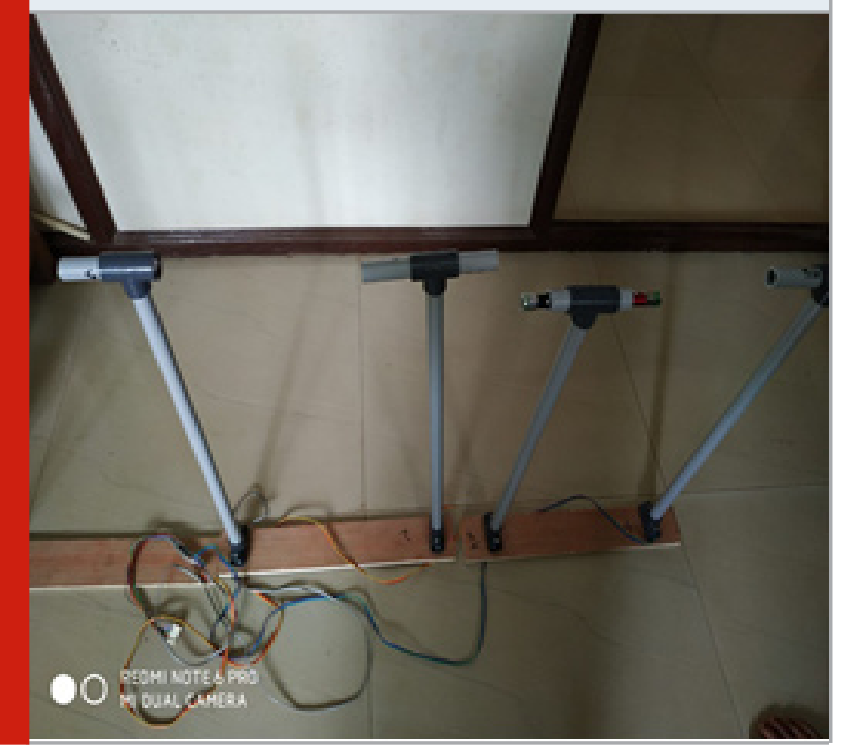

Figure 9: Circuit diagram for smart parking

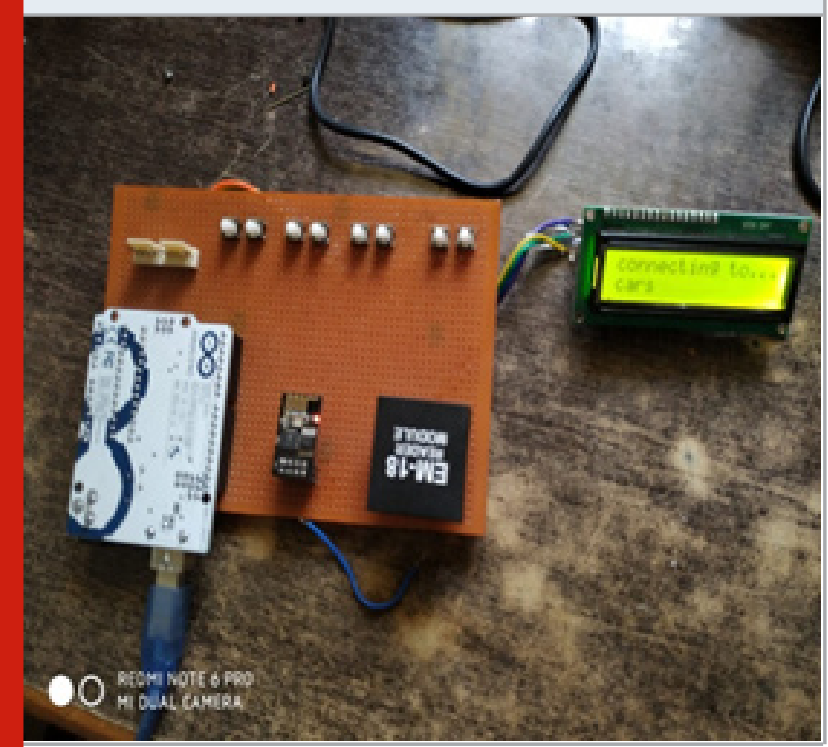


B. XAMPP SERVER: The local web server is developed by XAMPP server. It is light weight Apache distribution. XAMPP stands for Cross-Platform (X), Apache (A), MariaDB (M), PHP (P)and Perl(P).it is developed for deployment and testing. XAMPP acts as a local host. A server scripting language used is PHP. Web application is developed by Perl language. The web browser can be used to enter local host address. (Figure 7) represents the block diagram of the System. The NodeMCU (ESP8266)is used for wireless communication. It will send and receive data on internet remotely. The NodeMCU (ESP8266) will provide access to WiFi network. So it is working as Access Point (AP Mode) forother devices. Then further it connects to a wired network. We can use Android phone to send command/message to ESP8266. (Table 1) shows the System parameters.

Figure 10: Login Page

\section{$\equiv$ Home}

\section{Car Parking App}

Enter The Usemame

Enter The Password

LOGIN

\section{Model Working}

A. Sensor Stands: (Figure 8) shows sensor stand for parking system. Which has been used as a prototype to sense the presence of vehicle. Each stand has the facility for the placement of Ultrasonic sensor. Here each stand will be placed in each of the parking slots. As Ultrasonic sensor detects obstacle within the programmed range. Now the vehicle which enters within the range of the sensor will be detected and the information will be sent to the controller. Then the respective information about the availability of the parking slot will be updated.

Figure 11: Parking Slot Information

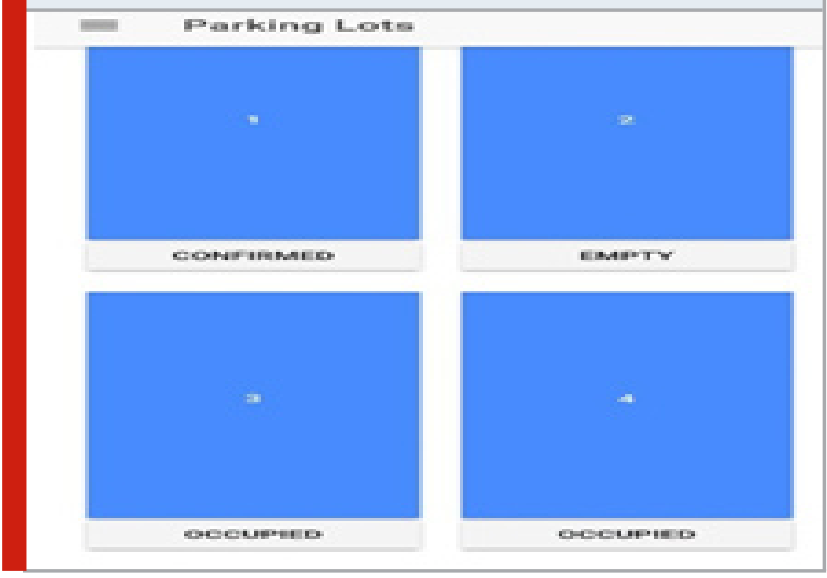

Table 2. Comparision of different vehicle parking systems

\begin{tabular}{|c|c|}
\hline & Modules used and its features \\
\hline $\begin{array}{l}\text { (Mendiratta et al., 2017) "Automatic } \\
\text { car parking system with visual } \\
\text { indicator along with IoT" }\end{array}$ & $\begin{array}{l}\text { Automatic car parking system makes } \\
\text { use of IoT with Arduino, Wi-Fi Module } \\
\text { (ESP8266), and Ultrasonic sensor for its implementation. } \\
\text { Feature provided: Provides feature for checking } \\
\text { the availability of the parking slot at the parking place using IoT. } \\
\text { Scope for improvement: But the module does not provide } \\
\text { feature for booking the parking slot using online } \\
\text { mode and also does not provide the cancellation feature. }\end{array}$ \\
\hline $\begin{array}{l}\text { (Khanna and Anand, 2016) } \\
\text { "IoT based Smart Parking System" }\end{array}$ & $\begin{array}{l}\text { The Model for smart parking system uses IoT along } \\
\text { with Raspberry Pi and Wi-Fi module. } \\
\text { Feature provided: The model provides feature for } \\
\text { online booking of the parking slot. } \\
\text { Scope for improvement: The model does not provide } \\
\text { feature for cancellation of the booked parking slot. }\end{array}$ \\
\hline Our proposed model & $\begin{array}{l}\text { The model uses Iot platform with Arduino, Ultrasonic } \\
\text { sensor and WiFi Module (ESP8266). } \\
\text { Feature provided: The model proposed features for online } \\
\text { booking and cancellation of the booked parking slot. } \\
\text { These features are added to improve the previous models } \\
\text { features. Theses are the enhanced features as compared } \\
\text { to the preicious models discussed above. }\end{array}$ \\
\hline
\end{tabular}

B. Circuit Diagram for Smart Parking: (Figure 9) shows the circuit diagram for controller, display unit, switch and RFID reader module. This RFID reader is used the 111 entry point to read the $\mathrm{QR}$ code generated by the user and validate. On LCD display will get the information about the entry of the vehicle. 
Figure 12: Parking Status Details

\section{$\equiv$ Parking Status Details}

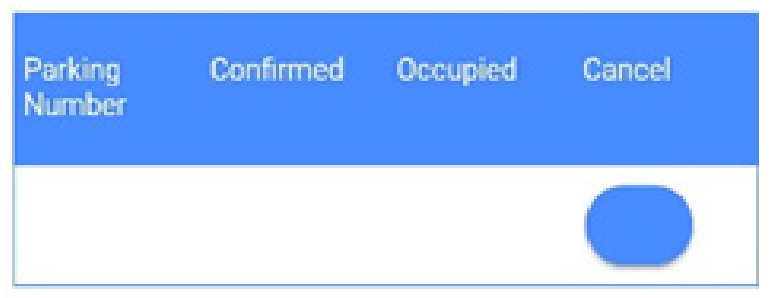

C. App Interface: (Figure 10) shows the login page of app interface used for our system. On this page new user can register. The already registered person can login here and proceed with checking the parking slot availability.

After the registration he will be able to login and check availability of parking slot as shown in (Figure 11). It consists of parking slot number and the parking slot is confirmed or not. After parking slot is occupied it will be displayed as occupied with that slot number else empty. Parking status details will be displayed as shown in (Figure 12). The customer has option to cancel his parking slot and it will update the status of parking slot.

Tables 3. Latency features of models

\begin{tabular}{|l|c|}
\hline & Latency features \\
\hline $\begin{array}{l}\text { (Mendiratta et al., 2017) "Automatic car } \\
\text { parking system with visual indicator } \\
\text { along with IoT" }\end{array}$ & $\begin{array}{c}\text { Bandwidth: } \\
7 \text { Mbps }\end{array}$ \\
\hline $\begin{array}{l}\text { (Khanna and Anand, 2016) "IoT based } \\
\text { Smart Parking System" }\end{array}$ & $\begin{array}{c}\text { Online booking timing delay: - } \\
\text { Cancellation timing delay: - }\end{array}$ \\
\hline Our proposed model & $\begin{array}{c}\text { Bandwidth: - } \\
\text { Online booking timing delay: } 125 \mathrm{~ms} \\
\text { Cancellation timing delay: - }\end{array}$ \\
\hline
\end{tabular}

\section{RESULT AND DISCUSSION}

(Mendiratta et al., 2017), the authors have proposed the information of availability of free car parking slots but there was no scope to have option of booking a slot in advance. (Khanna and Anand, 2016), in this second work the authors have implemented the booking option but there is no scope for cancelation. In our work we overcome both the drawbacks; our system gives free car parking slot option to book as well as to cancel the slot.

(Table 3) shows the latency features of the our model and the other previously implemented models.

\section{CONCLUSION}

In this proposed design of smart parking and reservation system, the concept of unique ID for each of the user with a RFID has been implemented. Once the user registers himself in the system then the system will store the user information in its data base and try to find the availability of space for the newly registered user. Using this concept of user registration the proposed design can be used to inform the user about the free slot of the parking place and also allows him to reserve the slot well in advance. And this system provides option of cancellation of booking. This makes the life of the vehicle user a lot more comfortable and intern saves his valuable time and fuel consumption. As we save the fuel we are reducing the whole carbon footprint which is the need of the hour.

\section{REFERENCES}

Chinrungrueng, J., Sunantachaikul, U. and Triamlumlerd, S. (2007) Smart parking: An application of optical wireless sensor network. International Symposium on Applications and the Internet Workshops. IEEE : 6666.

Chinrungrueng, J., Sununtachaikul, U. and Triamlumlerd, S. (2006) A vehicular monitoring system with powerefficient wireless sensor networks. 6th International Conference on ITS Telecommunications. IEEE : 951954.

Geng, Y. and Cassandras, C.G. (2011) A new "smart parking" system based on optimal resource allocation and reservations. 14th International IEEE Conference on Intelligent Transportation Systems (ITSC). IEEE : 979-984.

Khanna, A. and Anand, R. (2016) IoT based smart parking system. International Conference on Internet of Things and Applications (IOTA). IEEE : 266-270.

Krasner, G. and Katz, E. (2016) Automatic parking identification and vehicle guidance with road awareness. IEEE International Conference on the Science of Electrical Engineering (ICSEE). IEEE: 1-5. 
Lambrinos, L. and Dosis, A. (2013) DisAssist: An internet of things and mobile communications platform for disabled parking space management. IEEE Global Communications Conference (GLOBECOM). IEEE : 28102815.

Mendiratta, S., Dey, D. and Sona, D.R. (2017) Automatic car parking system with visual indicator along with IoT. International conference on Microelectronic Devices, Circuits and Systems (ICMDCS). IEEE : 1-3.

Polycarpou, E., Lambrinos, L. and Protopapadakis, E. (2013) Smart parking solutions for urban areas. IEEE 14th International Symposium on A World of Wireless, Mobile and Multimedia Networks (WoWMoM). IEEE : 1-6.

Suhr, J.K. and Jung, H.G. (2016) Automatic parking space detection and tracking for underground and indoor environments. IEEE Transactions on Industrial Electronics, 63(9) : 5687-5698.

Zheng, Y., Rajasegarar, S. and Leckie, C. (2015) Parking availability prediction for sensor-enabled car parks in smart cities. IEEE Tenth International Conference on Intelligent Sensors, Sensor Networks and Information Processing (ISSNIP). IEEE : 1-6. 